\title{
Distribution of bivalve larvae at a frontal system in the James River, Virginia*
}

\author{
Roger Mann \\ Virginia Institute of Marine Science, School of Marine Science, College of William and Mary, Gloucester Point, Virginia 23062, \\ USA
}

\begin{abstract}
The James River is the southernmost of the major subestuaries of the Chesapeake Bay, USA. A frontal system develops on the early flood tide in the Hampton Roads region of the lower James. This system, together with a cyclonic gyre in Hampton Roads, is in part responsible for partial retention of downstream-flowing water in the estuary and it's injection into deeper, upstream-flowing water. The role of the frontal system in retention of bivalve larvae in the James was investigated in a 2-part study: a field examination of larval distribution versus depth along a transect across the front in relation to salinity and temperature of the converging and diverging water masses, and a laboratory examination of the ability of oyster Crassostrea virginica larvae to swim in and through salinity gradients comparable to or greater than those encountered near the frontal system. Field studies indicate that larvae are passively transported through the frontal system and plunge to depth as the more saline water in which they are entrained encounters less saline water The deeper, more saline water flows upstream as it leaves the frontal system. Laboratory studies demonstrate that both straight hinge stage (mean length $=$ $75 \mu \mathrm{m}$ ) and umbo stage (mean length $=157.5$ to $159.7 \mu \mathrm{m}$ ) larvae actively swim through a salinity discontinuity of $3 \%$ when exposed in a column of $22 \%$ water overlayed by $19 \%$ water (extreme values characteristic of bottom and surface water at the frontal system). Further, their mean rates of vertical movement $\left(0.37\right.$ to $1.02 \mathrm{~mm} \mathrm{~s}^{-1}$ ) illustrate the ability of larvae to move through the depth of the water column in the James in less than one tidal cycle. Pediveliger stage oyster larvae (mean length $317.2 \mu \mathrm{m}$ ), by contrast, restricted swimming to small but trequent excursions above the bottom in the laboratory apparatus and did not swim through the salinity interface. Following passive transport through the frontal system in the lower James straight hinge and umbo stage larvae may employ active depth regulation to redistribute throughout the water column; however, pediveliger stage larvae probably remain near the sediment-water interface.
\end{abstract}

\section{INTRODUCTION}

The James River is the southernmost of the major subestuaries of the Chesapeake Bay, USA. The estuarine portion of the river is characterized by some 61775 hectares of oyster reefs (Haven \& Whitcomb 1983). These oyster reefs support a considerable commercial fishery and have been the focus of much attention (Baylor 1894, Moore 1911, Loosanoff 1932, Andrews 1951, 1954, 1982, Haven et al. 1981a,b). The temporal variability of successful settlement and metamorphosis of oyster Crassostrea virginica Gmelin larvae on clean substrate in the James has been described by Andrews $(1951,1954,1982)$ and Haven \& Fritz (1985). Basically, settlement occurs from June to

\footnotetext{
- Contribution No. 1479 from the Virginia Institute of Marine Science, College of William and Mary
}

early October with highest levels of settlement occurring in August and September. The timing of the peak of settlement is somewhat later than observed in the more northerly subestuaries of the Chesapeake Bay.

The consistency of the annual settlement of oysters in the James has long prompted study of the origin of the larvae which settle in that location. Extensive field studies of larval occurrence have been carried out; however, agreement on larval transport is lacking (see data in and commentary by Wood \& Hargis 1971, Andrews 1979, 1983). This is probably a reflection of the fact that investigators did not, at the time, have available to them a comprehensive description of circulation in the James to aid in sampling design. Recently Ruzecki \& Hargis (in press) have summarized extensive data of Ruzecki \& Moncure (1969) obtained from studies using the James River hydraulic model at Vicksburg, Mississippi during 1968. Their data suggest 
that surface circulation is characterized by a major downstream flow on the southerly bank of the river and a cyclonic gyre in the Hampton Roads region near the mouth of the river. Their data also suggest that surface water may be entrained by this gyre and returned to the upstream-flowing bottom water in the Hampton Roads area (see Fig. 1, after Ruzecki \& Hargis in press).

The summary of Byrne et al. (1987) and Kuo et al. (in press) progresses from that of Ruzecki \& Hargis (in press) and describes a frontal system that develops on the flood tide off Newport News (Figs. 1 and 2). The frontal system occurs during every flood tide under normal lunar variation. It is marked by a surface feature (foam lines, litter accumulation, changes in surface roughness) under most conditions. The formation of the frontal system is due predominantly to the phase difference of the tidal currents in the Hampton Roads region. The currents over Hampton Flats (Fig.1) lead the currents in the major shipping channel (Fig, 2), and both lead the current upstream of Newport News Point. Early flood currents pass over Hampton Flats as the water in the ship channel is slack and encounter ebbing water from the James River at Newport News Point. The more saline flooding waters dive beneath the fresher waters, an action augmented by the steep bottom topography at Newport News Point. As the flood current progresses along the shipping channel a second frontal system is formed. This progresses upriver with the flooding tide to converge with the frontal system already present. The circulation of the cyclonic gyre in Hampton Roads enhances the strength of the flood current during the early flood. The front travels with a speed of several $\mathrm{m} \mathrm{min}^{-1}$ and eventually comes to rest with the surface feature corresponding in position to a steep change in bottom topography south of Newport News Point in ca $9 \mathrm{~m}$ of water. Studies reported by Kuo et al. (in press) illustrate that dye released downstream of the frontal system will be transported to the frontal system in the surface layer of water $(<5 \mathrm{~m}$ in depth, maximum concentration at $<3 \mathrm{~m}$ depth) and will submerge completely at the surface feature to produce an upstream dye concentration maximum at 6 to $7 \mathrm{~m}$, concurrent with the depth of maximum vertical salinity gradient. This system therefore causes an injection of surface water into deep, upstream-flowing water.

The objective of this study was to critically assess the role of this frontal system in controlling distribution of oyster larvae. This assessment had 2 components: a field study to examine larval distribution versus depth along a transect across the front in relation to salinity and temperature of the converging and diverging water masses, and a laboratory study to examine the ability of bivalve larvae (here characterized by the oyster Crassostrea virginica) to swim in and through gradients of salinity comparable to or greater than those encountered near the frontal system. Larval studies addressed 3 specific questions: (1) Are there

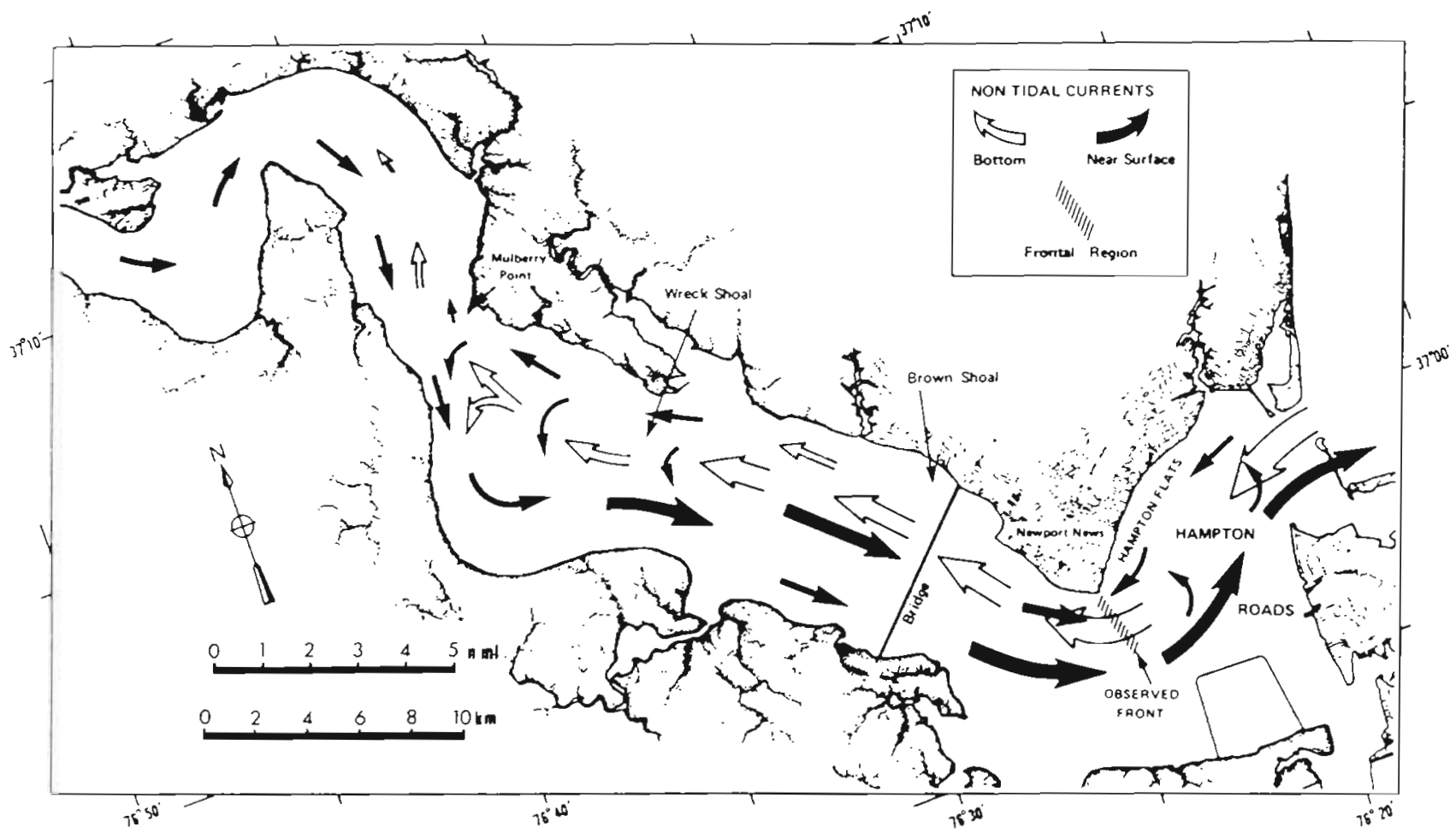

Fig. 1. Hypothesised surface and bottom non-tidal circulation in the James River Estuary (modified from Ruzecki \& Hargis in press) 


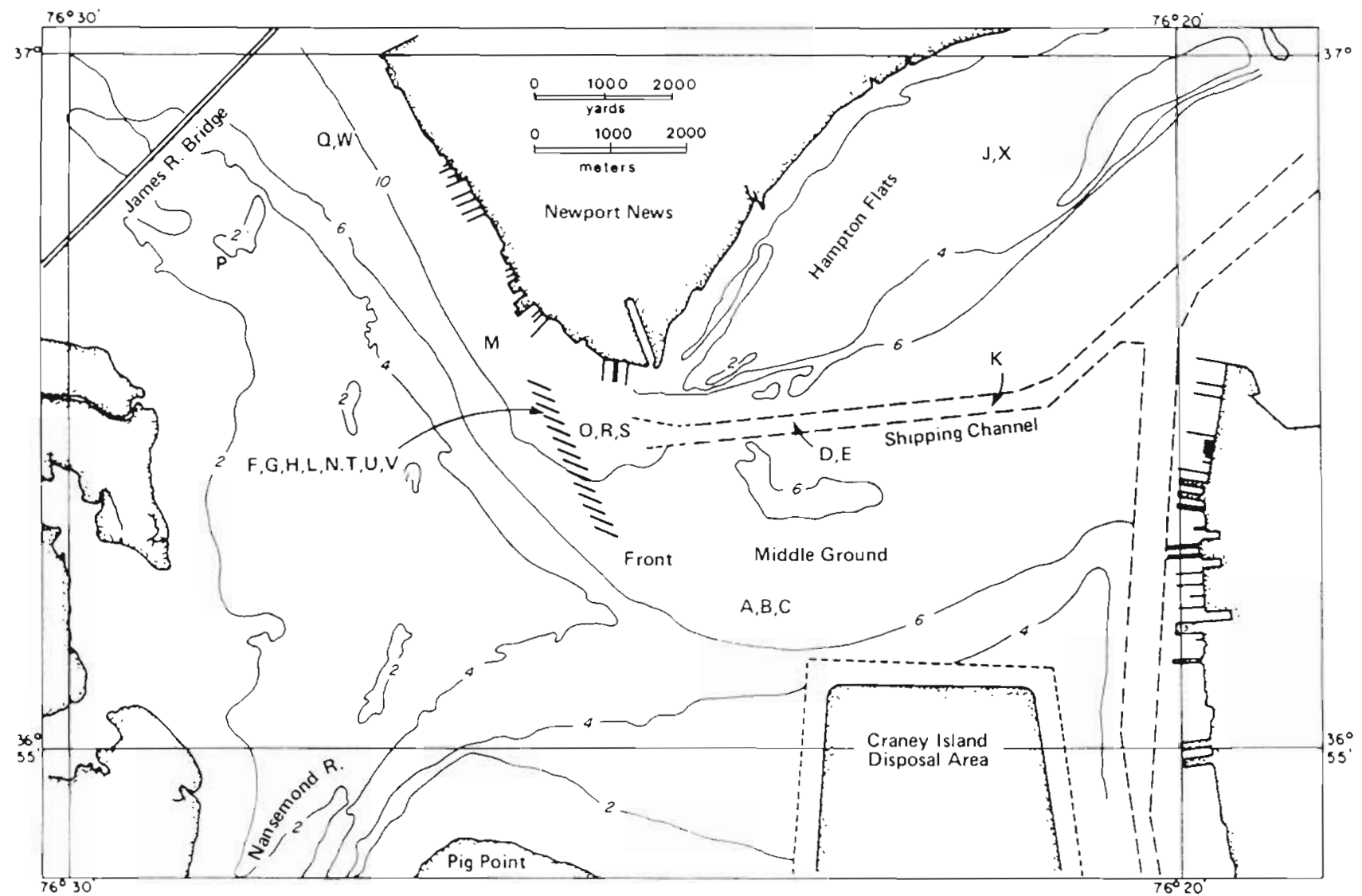

Fig. 2. Location of plankton sample collection sites during field studies, 6 to 20 Sep 1985. Major shipping channel is marked by heavy broken lines. Depths in $\mathrm{m}$

differences in numbers and sizes of larvae in the various water masses (as characterized by salinity and temperature) which converge at the frontal system? (2) Are larvae passively transported through the frontal system? (3) If larvae are passively injected into high salinity, deep, upstream-flowing water at the frontal system, will they subsequently swim upwards into overlaying, low salinity water and be subjected to downstream flow?

\section{MATERIALS AND METHODS}

Field studies. The sites of sample collection and the respective sample references are illustrated in Fig. 2; dates, times, depths and volumes sampled are given in Table 1. Plankton samples $Q$ and $W$, collected upstream of the frontal system near the James River Bridge, characterize the water mass flowing downstream on the northeastern shore of the James. Sample $P$ characterizes water flowing downstream on the southwestern shore of the James to become part of the cyclonic gyre in Hampton Roads. Samples A, B and C, collected to the south of Middle Ground in Hampton
Roads, and Samples J and $\mathrm{X}$, collected on the northeast end of Hampton Flats, characterize high salinity Hampton Roads water flowing upstream toward Newport News Point on flood tide. To examine possible passive transport of larvae through the frontal system a further series of samples ( $K, D, E, O, R, S, F, G, H, L, N, T, U, V)$ was collected on a transect that ran parallel to the direction of the current to bisect the frontal system.

The protocol at each sampling site was to first characterize the water column for salinity and temperature versus depth using a conductivity-temperaturedepth (CTD) profiling instrument (Applied Microsystems Inc.). Real time data readout was available and supplemented where available with data from dye studies as reported by Kuo et al. (in press). Each characteristic water mass was then sampled from its mid depth using a plankton pump as described below. The transient and mobile nature of the front required that the sampling be effected in a short time span, typically under 3 to $4 \mathrm{~h}$ for all samples on one tide. By characterizing both the water mass and the larval population at closely spaced sites across the front it was possible to determine whether or not larvae moved passively with the water masses. 
Field studies examined the numbers and sizes of larvae at sites both away from the frontal system and on a transect through the frontal system. Sampling is described for 3 dates; 6, 19 and 20 September 1985. During sampling the frontal system was evident as a distinct surface feature which was used as a visual guide for sampling. Plankton sampling involving the towing of nets of known mesh size was not practical in the present study due to stratification of the water column, the narrow depth ranges occupied by certain of these strata, and the direction of flow of these strata. A plankton pump was therefore used. Its design was modified from that of Taggart \& Leggett (1984). The pump was powered by a 3 hp Briggs and Stratton gasoline engine connected, without gear reduction, to a cast iron pump head. The engine had a variable throttle $(800$ to $3000 \mathrm{rpm})$ which allowed control of pumping speed. To the intake side of the pump were connected 2 to 5 lengths of reinforced rubber hose (Hampton Rubber Company, Hampton, VA 23661, USA) depending upon the depths to be sampled. Each hose measured $3 \mathrm{~m}$ in length and $5 \mathrm{~cm}$ internal diameter. Lengths were connected using male-female camlock connectors. The final section of pipe had a foot valve to aid in priming the pump. The outlet side of the pump was connected to a PVC T-junction, each side of which was closed by a gate valve ( $A$ and $B$ ). With valve $A$ open and $B$ closed water ran to waste through an exit pipe over the rail of the boat. In this manner the intake Iine was flushed between samples. With valve A closed and $B$ open, water flowed through a reducer to a $2.5 \mathrm{~cm}$ internal diameter PVC pipe of $45 \mathrm{~cm}$ total length. Fifteen $\mathrm{cm}$ from the terminal end of this pipe was a $\mathrm{T}$ valve holding the impeller portion (Rytor sensor) of a flowmeter (model 900T, Data Industrial, Pocasset, MA 02559, USA). Upon leaving the flowmeter the PVC pipe diameter was increased to $5 \mathrm{~cm}$ and connected to $3 \mathrm{~m}$ of $5 \mathrm{~cm}$ internal diameter, reinforced rubber pipe. The latter was hung over the rail of the boat. To its end was connected a $5 \mathrm{~cm}$ to $15 \mathrm{~cm}$ reducer-expander. The net mouth of a $30 \mathrm{~cm}$ diameter net was pleated and clamped on the $15 \mathrm{~cm}$ expander using 2 large hose clamps. The net had a $3 \cdot 1$ aspect ratio, a diagonal mesh measurement of $80 \mathrm{um}$, and a removable bucket of the same mesh (Sea Gear Corporation, Hileah Gardens, FL 33016, USA). When operating the net was immersed to its mouth to reduce damage to retained plankton. The volume of water sampled was between 251 and $1296 \mathrm{l}$. Flow rate during sampling was ca $100 \mathrm{lmin}^{-1}$

Upon collection samples were transferred to $500 \mathrm{ml}$ polyethylene bottles and, on return to the dock (a maximum of $3 \mathrm{~h}$ after collection) stained with Neutral Red and fixed in $5 \%$ (by volume) buffered formalin. On return to the laboratory samples were reduced by pre- filtration through a $1000 \mu \mathrm{m}$ mesh (to remove large debris) and filtration through a $37 \mu \mathrm{m}$ mesh to retain plankton, and transferred to a screw-top vial containing $95 \%$ ethyl alcohol. All further manipulations of larvae and other plankton were effected in ethanol. Samples were size-fractionated into $<150,150$ to 250 and $>250 \mu \mathrm{m}$ using appropriate nylon meshes (Tetko Inc, Elsford, NY 10523, USA). Larvae were then separated from inorganic debris and other plankton by hand under a dissecting microscope. Separated larvae were preserved in ethanol, and subsequently counted, measured to length (maximum dimension) and, where possible, identified to species using the key of Chanley \& Andrews (1971), Larvae of the oyster Crassostrea virginica were the most abundant. Data are expressed as total numbers of larvae in all size classes and oyster larvae in the 2 larger size classes.

Laboratory studies. Downstream-flowing surface water on the northeastern shore of the James at Newport News was characterized during the summer and fall of 1985 by a salinity of $19 \%$ and a temperature of $22^{\circ} \mathrm{C}$ (present study and Kuo et al. in press). Water flowing upstream over Hampton Flats toward the convergence was characterized at $22 \%$ salinity and $22^{\circ} \mathrm{C}$. These 2 sets of characteristics were taken as the basis for the laboratory studies.

Oyster larvae at various stages of development were obtained from the Virginia Institute of Marine Science (VIMS) hatchery. Details of oyster spawning procedure and larval culture follow the techniques previously described for the hard clam Mercenaria mercenaria L. by Castagna \& Kraeuter (1981). For the present study oysters were maintained at elevated temperatures throughout the fall, winter and spring of 1985-86 to encourage development of gonadal material. Ripe oysters were spawned by thermal stimulation, the resultant eggs fertilized and the cultures maintained in water originating from the York River at Gloucester Point. No attempt was made to control the salinity of the culture water, which varies with both tide and season; hence the need for acclimation of larvae prior to experimentation as described below. Relevant details describing size of the larvae examined are given in 'Results'. Larvae used in experiments were acclimated for a period of 24 to $48 \mathrm{~h}$ in $1 \mu \mathrm{m}$ filtered seawater in the presence of food (Isochrysis galbana Parke at 100 cells $\mathrm{ul}^{-1}$ ) to $22 \%$ salinity water at $22^{\circ} \mathrm{C}$. Acclimation was effected in the dark. Gentle aeration was provided during acclimation. Larval swimming behaviour was examined using the apparatus described below and illustrated in Fig. 3. The larvae were introduced into the bottom of a laboratory-generated water column in which $19 \%$ salinity water was supported by $22 \%$ salinity water. The junction between the 2 water masses was distinct. The entire water column was 


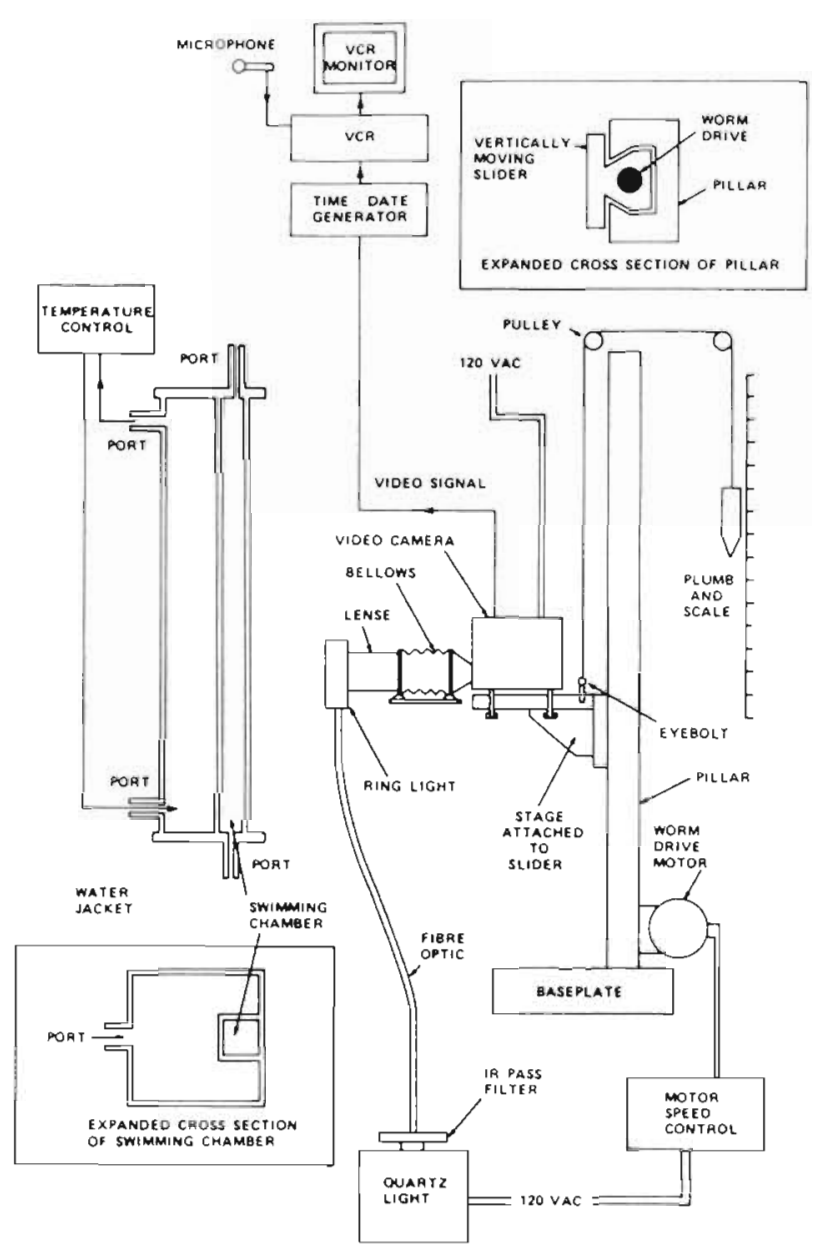

Fig. 3. Apparatus for recording swimming behaviour of oyster larvae in the presence of a salinity discontinuity. A complete description is given in the text. For clarity the light proof box enclosing the swimming chamber and camera/moving stage has been omitted. Supplementary illumination of the swimming chamber from above by a second fibre optic was available but rarely used (see text)

maintained at $22^{\circ} \mathrm{C}$. Larvae were subsequently observed, using the video system described below, to ascertain whether or not they would pass through the $19 / 22 \%$ interface and then remain in the less saline water. This salinity gradient is clearly more intense than would be encountered in the field even though the absolute values either side of the gradient are comparable. The rationale was applied that if larvae can swim through the intense gradient in the laboratory system then they would also swim through the less intense gradient encountered in the field. In addition, the rate of vertical movement of the larvae was recorded to allow estimation of the time required for a continually swimming individual to ascend through the complete water column in the James at Newport News Point.
In order to simultaneously examine the influence of one or more environmental stimuli on swimming behaviour 2 swimming chambers were constructed. Chambers of 29 and $59 \mathrm{~cm}$ height were used. Both chambers were of sufficient width to allow swimming to proceed in a helical pattern without the vertical walls influencing swimming, i.e the larvae must not collide with the wall, have to alter the shape of the helix to avoid collision with the wall or be influenced by drag associated with movement near a wall (Fig. 3). If the larva is considered to be a flattened elipsoid growing from ca $100 \mu \mathrm{m}$ to ca $250 \mu \mathrm{m}$ diameter during development, estimates of appropriate Reynolds numbers can be made, and from these the appropriate minimum dimensions to avoid wall-related drag calculated (for an example of such calculations see Vogel 1981). The minimum wall-to-larva distance required for a $250 \mu \mathrm{m}$ larva is ca $0.25 \mathrm{~mm}$. If twice this value is added to the largest diameter so far recorded for a larva swimming in a helical pattern (a value of $3.5 \mathrm{~mm}$ from Cragg \& Gruffydd 1975), a value of $4 \mathrm{~mm}$ is obtained. A minimum horizontal dimension of $5 \mathrm{~mm}$ was used to allow unimpeded swimming in the center of the chamber (see below). The chambers were constructed from optically clear plexiglass; this has higher transparency than borosilicate glass in the infrared (93\% at $1000 \mathrm{~nm}$ versus $85 \%$ for glass) and retains this transparency past $1200 \mathrm{~nm}$ whereas transparency decreases for borosilicate at these wavelengths. This transparency to IR was crucial for photography as will be discussed later in the text. Temperature in the chamber was controlled at $22^{\circ} \mathrm{C}$ by a water jacket which enclosed 3 sides of the chamber; the 4 th side remained open for viewing. The water jacket was connected to an independent, temperature-controlled, recirculating water bath.

Salinity gradients were made by sequential loading of the chamber with water of varying salinity through either the top or bottom port (Fig.3). A variable intensity white light source was positioned at the top of the chamber (omitted from Fig. 3 for clarity). To facilitate photography the chamber was illuminated horizontally by an IR light source (Fiber Optic Specialties Inc., Peabody, MA, USA, model LS81A fiber optic, with a FA-83 Filter Adapter and either a 695 or $850 \mathrm{~nm}$ long pass filter: Oriel Corp, Stratford, CT, USA) from a ring light attached to and surrounding the lens of a vertically moving video camera. Thus, photography proceeded independently of the color and intensity of light illuminating the larvae as a phototactic stimulus from above. The experimental chamber could, therefore, be used to provide gradients light and salinity in combination as desired.

The previous studies of Cragg (1980) and Mann \& Wolf (1983) both used travelling microscopes to 
observe larval swimming. In these experiments the travelling microscope was replaced by a high resolution, IR-sensitive video camera (Dage-MTI SC65S with Ultricon phototube) mounted on a vertically travelling stage (Velmex, Inc., E. Bloomfield, NY 14443, USA) (Fig. 3). The stage was driven by a Bodine S4 1 motor and Minarik SL-15 speed control allowing a variable speed traverse from 0.1 to $10 \mathrm{~mm} \mathrm{~s}^{-1}$ - encompassing larval swimming speeds as recorded in the literature (see review by Mann 1986a). Low intensity light levels are not problematic in that the SC65S operates optimally at $<0.1$ foot candles.

Even with high resolution photography, limitations exist depending upon the magnification and depth of field required. As the former increases the latter decreases. Bivalve larvae generally swim in vertically oriented helices (Cragg 1980). Video observation and recording ideally maintain the entire swimming movement in the $X$ (left-right) and $Z$ (front-back) planes in focus while extended movement in the $Y$ (up-down) plane is accommodated by the travelling stage. Literature values (Cragg \& Gruffydd 1975, Table 2; Mann \& Wolf 1983, Table 1 ) show that the $X$ and $Z$ displacements do not exceed $3.5 \mathrm{~mm}$. With larvae of $<100$ to $250 \mu \mathrm{m}$ maximum dimension only small lateral magnifications $(<15$ to $20 x)$ can be used if depth of field is to be maintained. The Dage camera was therefore fitted with macro-optics (Nikon PB-6 bellows, $50 \mathrm{~mm}$ Series $E$ Nikon lens). For each experiment the camera focus was fixed at the beginning of the experiment. The complete experimental apparatus (chamber, camera, moving stage) was enclosed in a light-proof box (omitted from Fig. 3 for clarity) to eliminate the influence of laboratory lighting on larval behaviour and provide a constant light environment, controlled by the predetermined setting of the IR and white light sources, for photography. Vertical movement of the camera was controlled by external switching of the variable speed motor drive on the camera mounting stage. The vertical position of the camera was recorded by a simple pulley and plumb-bob system on a externally mounted meter stick (Fig. 3). Video signals were observed on a Panasonic WV-5410 monitor, recorded on a Panasonic NV-8950 VCR and overlayed with the time and date (Panasonic WJ-810 time-date signal generator) and sound commentary.

In order to obtain a water source of fixed salinity seawater was obtained from the VIMS Eastern Shore Laboratory at Wachapreague, Virginia. Water was transported in $20 \mathrm{l}$ polyethylene (Nalgene) carboys to Gloucester Point where it was filtered $(1 \mu \mathrm{m})$ and diluted from its original salinity ( $>30 \%$ as measured using a salinometer calibrated against Copenhagen water) to either 19 or $22 \%$ using distilled, deionized water The diluted products were maintained at $4{ }^{\circ} \mathrm{C}$ in the dark until $1 \mathrm{~d}$ before use, when they were transferred to a $22^{\circ} \mathrm{C}$ water bath prior to experimental use.

Prior to introducing the larvae into the experimental chamber the latter was equilibrated to $22^{\circ} \mathrm{C}$ by continual recirculation of $22^{\circ} \mathrm{C}$ water through the attached water jacket. A calibrated (in mm) plexiglass ruler was introduced into the chamber equidistant between its front and back walls (with respect to the 'view' of the camera) and the video camera focussed on the ruler. The magnification was adjusted, using the bellows, until a distance of ca $4 \mathrm{~mm}$ filled the vertical displacement on the monitor screen. The camera focus and magnification were then fixed and a recording made of the ruler scale on the VCR tape. This scale provided the basis for all subsequent measurements of larval swimming rate from that experiment's recordings.

Two protocols were used, these differing depending upon the chamber used. With the larger chamber $1590 \mathrm{~mm} \mathrm{H} \times 15 \mathrm{~mm} \mathrm{~W} \times 15 \mathrm{~mm} \mathrm{D}) 19 \%$ salinity water was introduced through the bottom port. Subsequently $22 \%$ water was introduced slowly through that same port. The result was a water column ca $40 \mathrm{~cm}$ high comprised of $20 \mathrm{~cm}$ of $19 \%$ water over $20 \mathrm{~cm}$ of $22 \%$ water. The interface between the two, as shown by earlier dye studies, was very sharp, less than $1 \mathrm{~mm}$ in thickness, and stable over a period of up to $1 \mathrm{~d}$. Once the '2 layer' water column was produced larvae were carefully introduced through the bottom port in a small volume of $22 \%$ water. This transfer was effected in dim laboratory lighting. Following the transfer the lightproof box enclosing the apparatus was sealed and the clock feature on the time-date generator started. The larvae were observed to ensure that they were swimming, using the camera. The camera was then used to scan the chamber at intervals of $5 \mathrm{~cm}$ depth. At each depth the camera remained stationary for $10 \mathrm{~s}$ to obtain a 'still'. One scan required less than $3 \mathrm{~min}$. The scan was repeated every 5 to $10 \mathrm{~min}$ throughout the experimental period. The time series of scans allowed observation of swimming throughout the depth of the column with special emphasis on the salinity interface. Recordings of larval swimming for rate estimation were made with the camera at a fixed height. Measurement of individual larval swimming speed were made from replay of the VCR tapes. Measurements were restricted to larvae which swam in the center of the chamber and were unimpeded by collision with the chamber walls. A grid, corresponding to the ruler calibration, was temporarily fixed to the VCR monitor and the tape replayed at reduced speed. The vertical movement of larvae across fixed intervals of grid was timed using the time-elapsed recording on the VCR tape. A measurement of mean rate of vertical movement for each size of Iarva examined was thus obtained. (Note that this is the ecologically relevant value in terms of rate of depth 
regulation; it differs from absolute swimming speed because the larva swims in a helical pattern)

On termination of the experiment (typically 3 to $4 \mathrm{~h}$ ) the chamber was sequentially unloaded through the bottom port and a subsample of water removed for every $10 \mathrm{~cm}$ of column depth. The salinity of these subsamples was examined and the results plotted to ensure that no disruption of the salinity gradient had occurred during the experimental period. No disruption was noted in any of the experiments. Larvae were retained on a $53 \mu \mathrm{m}$ nylon mesh, fixed in $5 \% \mathrm{v} / \mathrm{v}$ buffered formalin, and subsequently measured to obtain a value for mean individual length using a compound microscope equipped with a calibrated ocular micrometer

Experiments performed with the smaller swimming chamber $(290 \mathrm{~mm} \mathrm{H} \times 7 \mathrm{~mm} \mathrm{~W} \times 5 \mathrm{~mm} \mathrm{D})$ used the following protocol. Larvae were introduced through the top port of the chamber by gentle pipetting in $22 \%$, $22^{\circ} \mathrm{C}$ water until the latter filled the chamber to half of its depth. This transfer was performed in dim light and with the light-proof box sealed. Larval swimming was observed on the VCR monitor until larvae were actively swimming through the water column and remaining at or near the meniscus. Then, in dim light, the light-proof box was opened and by pipetting through a fine capillary, $19 \%$ water was overlayed on the $22 \%$ water to fill the chamber to its full depth. The light-proof box was then quickly sealed, the 'time elapsed' clock started, and procedures for time-series, vertical scanning of the chamber and swimming rate measurement effected as for the previous protocol. Dye studies again illustrated that salinity interfaces could be constructed and maintained by this method. At the end of an experiment the column was unloaded from the top and the larvae retained and fixed as described earlier.

In summary, 2 protocols examining larval swimming in the $19 \%$ over $22 \%$ at $22{ }^{\circ} \mathrm{C}$ environment were used. No other salinity or temperature environments were examined. The role of light in swimming received only cursory examination but appeared to be of minor influence as illumination from above with white light did not alter swimming activity as observed in the dark (i.e. IR illumination). Consequently, the vast majority of experiments were confined to examination of swimming with only the IR light source, necessary for photography, illuminated.

\section{RESULTS}

\section{Field studies}

Bivalve larvae, including oyster larvae, were present in all samples collected (Table 1). Each of the 3 sampling days examined a slightly different array of samp- ling sites due to limited time within the appropriate phase of the tide. Broad spatial coverage was obtained on 6 September while more intensive sampling in the frontal region was accomplished on 19 and 20 September.

Of the samples collected on 6 September, the waters of Newport News channel east of the frontal system (Samples D and E) exhibited the lowest numbers per $100 \mathrm{l}$ of all larvae combined (Table 2); however, the numbers of oyster larvae of $>150 \mu \mathrm{m}$ length were higher than all other samples except $G$ (Fig. 2). The deeper sample (E) from Newport News channel was notably lower in $<150 \mu \mathrm{m}$ larvae as a percentage of total larvae but contained comparable numbers of oyster larvae in the $>150 \mu \mathrm{m}$ classes. The water column immediately to the west of the frontal system was sampled at 2,4 and $7 \mathrm{~m}$ depth. The $2 \mathrm{~m}$ sample $(F)$, essentially ebbing water on the northern shore of the James River, was characterized by a very high $(92 \%)$ proportion of $<150 \mu \mathrm{m}$ larvae, low numbers of 150 to $250 \mu \mathrm{m}$ oyster larvae and the absence of $>250 \mu \mathrm{m}$ oyster larvae (Table 2 ). The low values for $>150 \mu \mathrm{m}$ oyster larvae seen in the $2 \mathrm{~m}$ depth sample are not comparable with those seen in the $4 \mathrm{~m}(\mathrm{G})$ and $7 \mathrm{~m}(\mathrm{H})$ samples. The numbers of $>150 \mu \mathrm{m}$ oyster larvae and the percentage of $<150 \mu \mathrm{m}$ larvae in the $4 \mathrm{~m}$ and $7 \mathrm{~m}$ samples from west of the front are comparable to that recorded at $2 \mathrm{~m}$ (D) in the Newport News channel. The strong similarity in temperature and salinity (Fig. 4) at sample sites D $\left(27^{\circ} \mathrm{C}\right.$, $20.5 \%), G\left(27.5^{\circ} \mathrm{C}, 20.5 \%\right)$ and $\mathrm{H}\left(26.8^{\circ} \mathrm{C}, 21 \%\right)$ support the concept that surface water originating in Newport News channel passively carries larvae as it 'plunges' with east to west movement through the frontal system. The deep water sample (E) from $7 \mathrm{~m}$ in the Newport News channel is at a temperature and salinity $\left(26.2^{\circ} \mathrm{C}, 24 \%\right)$ corresponding to a depth of $15 \mathrm{~m}$ upstream of the front (Fig. 4) - a depth that was not sampled at the latter location.

Despite the similarities in Samples $D, G$ and $\mathrm{H}_{\text {, }}$ differences are apparent in the total number of larvae present per 1001 (Tables 1 and 2). The question arises as to whether or not bivalve larvae are concentrated in 'patches' in estuaries. The time required to collect a sample varied between 4 and 10 min dependent upon sample volume. Samples were collected in rapid succession. If 'patchiness' existed, it may or may not have been observed by the procedure depending upon its temporal and spatial stability and its co-occurrence with sampling. The present data cannot quantify the possible impact of patchiness; however, discontinuous distribution may have occurred during the course of the study.

Samples (A, B, C) from all depths at the Middle Ground station were characterized by a high percen- 
Table 1. Summary of bivalve larvae collected in field studies, 6 to 20 Sep 1985. All times are given as Daylight Saving Time. For Eastern Standard Time subtract 1 h e.g. 11:30 DST is 10:30 EST A to X is sample reference; for site of collection see Fig. 2. Depth and volume of sample are in $\mathrm{m}$ and 1 , respectively. Larval numbers are given as per sample and per $100 \mathrm{l}$ for the size classes $<150 \mu \mathrm{m}$ length (all species), 150-250 $\mathrm{um}$ and $>250 \mu \mathrm{m}$ length (oysters), 150-250 $\mu \mathrm{m}$ and $>250 \mu \mathrm{m}$ (all species except oysters) and a grand total

\begin{tabular}{|c|c|c|c|c|c|c|c|c|c|c|c|c|c|c|c|}
\hline \multirow[t]{3}{*}{ Sample } & \multirow{3}{*}{$\begin{array}{l}\text { Time } \\
\text { (h) }\end{array}$} & \multirow{3}{*}{$\begin{array}{l}\text { Depth } \\
(\mathrm{m})\end{array}$} & \multirow{3}{*}{$\begin{array}{l}\text { Vol. } \\
\text { (1) }\end{array}$} & \multicolumn{6}{|c|}{ Tota! } & \multicolumn{6}{|c|}{ Per 1001} \\
\hline & & & & \multirow{2}{*}{$\begin{array}{l}<150 \\
\text { um } \\
\text { all sp. }\end{array}$} & \multicolumn{2}{|c|}{ Oyster } & \multicolumn{2}{|c|}{ Other } & \multirow[t]{2}{*}{ Total } & \multirow{2}{*}{$\begin{array}{l}<150 \\
\mu \mathrm{m} \\
\text { all sp. }\end{array}$} & \multicolumn{2}{|c|}{ Oyster } & \multicolumn{2}{|c|}{ Other } & \multirow[t]{2}{*}{ Total } \\
\hline & & & & & $\begin{array}{c}150- \\
250 \mu \mathrm{m}\end{array}$ & $\begin{array}{r}>250 \\
\mu \mathrm{m}\end{array}$ & $\begin{array}{c}150- \\
250 \mu \mathrm{m}\end{array}$ & $\begin{array}{r}>250 \\
. . \mathrm{m}\end{array}$ & & & $\begin{array}{c}150- \\
250 \mu \mathrm{m}\end{array}$ & $\begin{array}{r}>250 \\
\mu \mathrm{m}\end{array}$ & $\begin{array}{c}150- \\
250 \mu \mathrm{m}\end{array}$ & $\begin{array}{r}>250 \\
\mu \mathrm{m}\end{array}$ & \\
\hline \multicolumn{16}{|c|}{6 September } \\
\hline A & $11: 30$ & 2 & 251 & 387 & 7 & 1 & 5 & 1 & 401 & 154 & 2.8 & 0.4 & 2 & 0.4 & 160 \\
\hline $\mathrm{B}$ & $11: 45$ & 4 & 767 & 475 & 16 & 2 & 8 & 1 & 502 & 62 & 2.1 & 0.3 & 1 & 0.1 & 65 \\
\hline $\mathrm{C}$ & $12: 00$ & 6 & 1296 & 841 & 43 & 6 & 114 & 13 & 1017 & 65 & 3.3 & 0.5 & 8.8 & 1 & 78 \\
\hline $\mathrm{D}$ & $12: 50$ & 2 & 688 & 321 & 35 & 6 & 8 & 0 & 370 & 47 & 5.1 & 0.9 & 1.2 & 0 & 54 \\
\hline$E$ & $13: 05$ & 7 & 635 & 232 & 29 & 6 & 97 & 39 & 403 & 37 & 4.6 & 0.9 & 15 & 6.1 & 64 \\
\hline F & $14: 20$ & 2 & 794 & 689 & 10 & 0 & 50 & 0 & 749 & 87 & 1.3 & 0 & 6.3 & 0 & 94 \\
\hline$G$ & $14: 25$ & 4 & 781 & 887 & 49 & 2 & 91 & 2 & 1031 & 114 & 6.3 & 0.3 & 12 & 0.3 & 132 \\
\hline $\mathrm{H}$ & $14: 30$ & 7 & 728 & 794 & 25 & 3 & 74 & 15 & 911 & 109 & 3.4 & 0.4 & 10 & 2.1 & 125 \\
\hline \multicolumn{16}{|c|}{19 September } \\
\hline $\mathrm{J}$ & $09: 40$ & 1 & 980 & 92 & 6 & 6 & 46 & 3 & 153 & 9.4 & 0.6 & 0.6 & 4.7 & 0.3 & 16 \\
\hline $\mathrm{K}$ & $09: 56$ & 2 & 980 & 1159 & 22 & 78 & 361 & 17 & 1637 & 118 & 2.2 & 8 & 37 & 1.7 & 167 \\
\hline $\mathrm{L}$. & $11: 30$ & 1.5 & 905 & 46 & 1 & 1 & 4 & 1 & 53 & 5.1 & 0.1 & 0.1 & 0.4 & 0.1 & 5.9 \\
\hline M & $11: 45$ & 5 & 905 & $339^{a}$ & 63 & 20 & 101 & 8 & 531 & 38 & 7 & 2.2 & 11 & 0.9 & 59 \\
\hline$N$ & $12: 10$ & 9 & 905 & 1154 & 53 & 4.9 & 122 & 43 & 1421 & 128 & 5.9 & 5.4 & 14 & 4.8 & 157 \\
\hline 0 & $12: 40$ & 5 & 1056 & 1020 & 52 & 114 & 224 & 9 & 1419 & 97 & 4.9 & 11 & 21 & 0.9 & 135 \\
\hline $\mathrm{P}$ & $13: 40$ & 3 & 829 & 1.7 & 5 & 9 & 12 & 3 & 46 & 2.1 & 0.6 & 1.1 & 1.4 & 0.4 & 5.5 \\
\hline$Q$ & $14: 05$ & 5 & 1018 & 236 & 37 & 18 & 35 & 15 & 341 & 23 & 3.6 & 1.8 & 3.4 & 1.5 & 34 \\
\hline \multicolumn{16}{|c|}{20 September } \\
\hline $\mathrm{R}$ & $12: 00$ & 7 & 980 & 930 & 19 & 13 & 63 & 7 & 1032 & 95 & 1.9 & 1.3 & 6.4 & 0.7 & 105 \\
\hline S & $12: 15$ & 2 & 942 & 179 & 14 & 19 & 65 & 11 & 288 & 19 & 1.5 & 2 & 6.9 & 1.2 & 31 \\
\hline $\mathrm{T}$ & $13: 25$ & 2 & 641 & 159 & 2 & 0 & 14 & 2 & 177 & 25 & 0.3 & 0 & 2.2 & 0.3 & 28 \\
\hline U & $13: 35$ & 5 & 528 & 36 & 4 & 24 & 26 & 14 & 104 & 6.8 & 0.8 & 4.6 & 4.9 & 2.7 & 20 \\
\hline V & $13: 45$ & 9 & 528 & 573 & 32 & 7 & 68 & 10 & 690 & 109 & 6.1 & 1.3 & 1.3 & 1.9 & 131 \\
\hline W & $14: 05$ & 1 & 528 & 117 & 14 & 5 & 25 & 1 & 162 & 22 & 2.6 & 1 & 4.7 & 0.2 & 31 \\
\hline$x$ & $1.4: 40$ & 1 & 565 & 46 & 4 & 12 & 12 & 3 & 77 & 8.2 & 0.7 & 2.1 & 2.1 & 0.5 & 14 \\
\hline
\end{tabular}

tage of $<150 \mu \mathrm{m}$ larvae and the presence of oyster larvae of $>150 \mu \mathrm{m}$ length (Tables 1 and 2). The percentage of $<150 \mu \mathrm{m}$ larvae decreased with depth; the numbers of oyster larvae of $>150 \mu \mathrm{m}$ increased with depth. No temperature and salinity data are available for this sampling site; however, from its position, to the northeast of the mouth of the Nansemond River (Fig. 2), and the state of the tide during sampling, slack before flood as indicated by surface water flow, certain statements can be made. Ruzecki (in Byrne et al. 1987)

Table 2. Characterization of plankton samples for 6 Sep. Each sample is characterized by the following values: depth of collection total number of larvae per $100 \mathrm{l} \%$ of larvae < 150 um length, number of oyster larvae 150 to $250 \mu \mathrm{m}$ length per 1001 , number of oyster larvae $>250 \mu \mathrm{m}$ length per 1001 . For sites of sample collections see Fig. 2

\begin{tabular}{|c|c|c|c|c|c|c|c|c|c|c|c|c|}
\hline \multicolumn{6}{|c|}{ Samples F-H } & & \multicolumn{6}{|c|}{ Samples D, E } \\
\hline F & $2 \mathrm{~m}$ & 94 & $92 \%$ & 1.3 & 0 & & & $2 \mathrm{~m}$ & 54 & $87 \%$ & 5.1 & 0.9 \\
\hline G & $4 \mathrm{~m}$ & 132 & $86 \%$ & 6.3 & 0.3 & & & $7 \mathrm{~m}$ & 64 & $58 \%$ & 4.6 & 0.9 \\
\hline \multirow[t]{5}{*}{$\mathrm{H}$} & $7 \mathrm{~m}$ & 125 & $87 \%$ & 3.4 & 0.4 & & & & & & & \\
\hline & & & & & \multicolumn{6}{|c|}{ Samples A-C } & & \\
\hline & & & & & A & $2 \mathrm{~m}$ & 160 & $96 \%$ & 2.8 & 0.4 & & \\
\hline & & & & & B & $4 \mathrm{~m}$ & 65 & $95 \%$ & 2.1 & 0.3 & & \\
\hline & & & & & C & $6 \mathrm{~m}$ & 78 & $83 \%$ & 3.3 & 0.5 & & \\
\hline
\end{tabular}



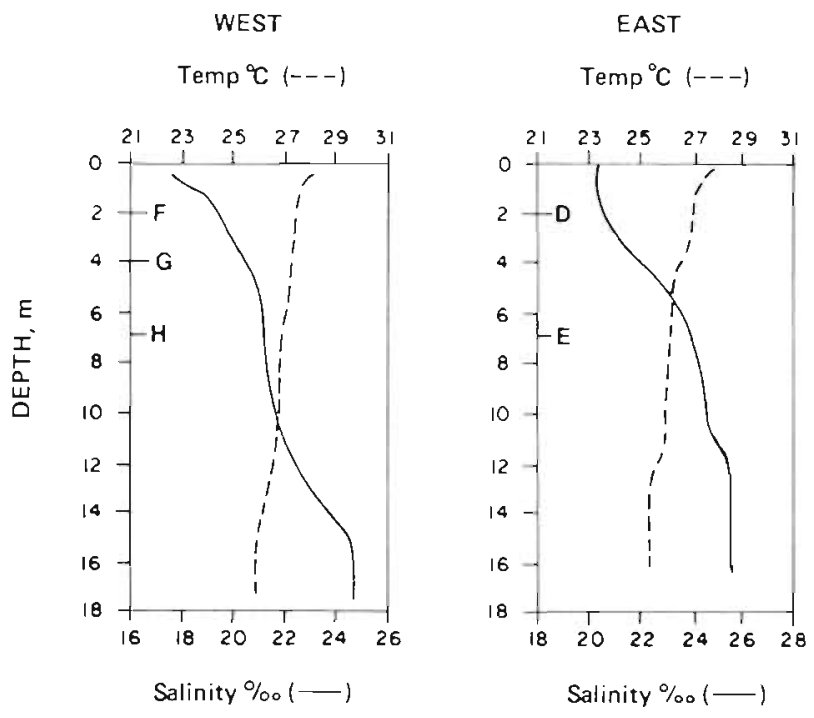

6 SEPT 1985

Fig. 4. Temperature $\left({ }^{\circ} \mathrm{C}\right)$ and salinity $(\%)$ profiles for water column at collection sites of Samples D to H inclusive, 6 Sep 1985. Depths of samples indicated by corresponding letter on the figure. For site locations see Fig. 2

states that an anticyclonic gyre forms at the mouth of the Nansemond during ebb tide in the James prior to the flood tide beginning at the mouth of the James. This gyre causes early localised flooding at the mouth of the Nansemond which subsequently intensifies as flooding commences in the James. Samples A and B contain notably high percentages of $<150 \mu \mathrm{m}$ larvae that probably originated from upstream of the station and were washed downstream with the ebbing tide. The deeper sample, $\mathrm{C}$, contains both a smaller percentage of $<150 \mu \mathrm{m}$ larvae and a greater absolute number of $>150 \mu \mathrm{m}$ larvae. The latter, in particular, may have originated upstream of the station in the James or the Nansemond, have been washed into Hampton Roads on preceeding tides and, on the sampled change of tide, have been washed back into the mouth of the Nansemond River.

Plankton sampling on 19 September included 4 sampling sites ( $J, K, P$ and $Q$ ) distant from the frontal system, plus sites ca $200 \mathrm{~m}$ east (O) and west ( $L, M$ and $\mathrm{N}$ ) of the surface feature. The Hampton Flats sample, J, contained low numbers of larvae and a comparatively low percentage of $>150 \mu \mathrm{m}$ larvae (Tables 1 and 3). Some oyster larvae of $>150 \mu \mathrm{m}$ length were present. By contrast the Newport News Channel sample, K, contained over an order of magnitude greater number of larvae and a notably high number of $>250 \mu \mathrm{m}$ oyster larvae (Table 1). The sample taken at $5 \mathrm{~m}$ depth and $200 \mathrm{~m}$ east of the front, $\mathrm{O}$, showed strong similarities to Sample $K$ in terms of numbers of larvae, percentage of larvae $<150 \mu \mathrm{m}$, and presence of $>150 \mu \mathrm{m}$ oyster larvae (Table 3). Samples J, K and O came from water of similar temperature and salinity ( $\mathrm{J}$ at $21.8{ }^{\circ} \mathrm{C}, 23.5 \%$; $\mathrm{K}$ at $22{ }^{\circ} \mathrm{C}, 23.5 \% ; \mathrm{O}$ at $22.3^{\circ} \mathrm{C}, 23.5 \%$; Fig. 5). An increasing number of larvae was seen with increasing depth $(1.5,5$ and $9 \mathrm{~m})$ to the west of the front (Tables 1 and 3 ). The $1.5 \mathrm{~m}$ sample, $\mathrm{L}$, was characterized by a high percentage of $<150 \mu \mathrm{m}$ larvae (the highest of any sample collected on that day) and very low concentrations of $>150 \mu \mathrm{m}$ oyster larvae. Higher (both absolute and proportionate) concentrations of $>150 \mu \mathrm{m}$ oyster larvae were seen at 5 and $9 \mathrm{~m}$. These values were similar to those observed at $5 \mathrm{~m}$ depth $200 \mathrm{~m}$ east of the front, Sample $O$, and at the Newport News

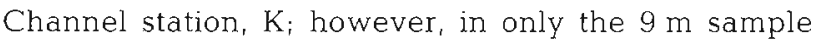
did the absolute numbers of larvae closely resemble Sample $O$ (Table 3). Fig. 5 illustrates the temperature and salinity profiles for sampling sites $J$ to $Q$ inclusive as occupied on 19 September. Samples L and $M$ are presented separately to Sample $\mathrm{N}$ as during sampling for $L$ and $M$ upstream drift of the vessel was recorded (Fig. 2). Prior to collection of Sample $\mathrm{N}$ the vessel was

Table 3. Characterization of plankton samples for 19 September Data display as for Table 2. For sites of sample collections see Fig. 2

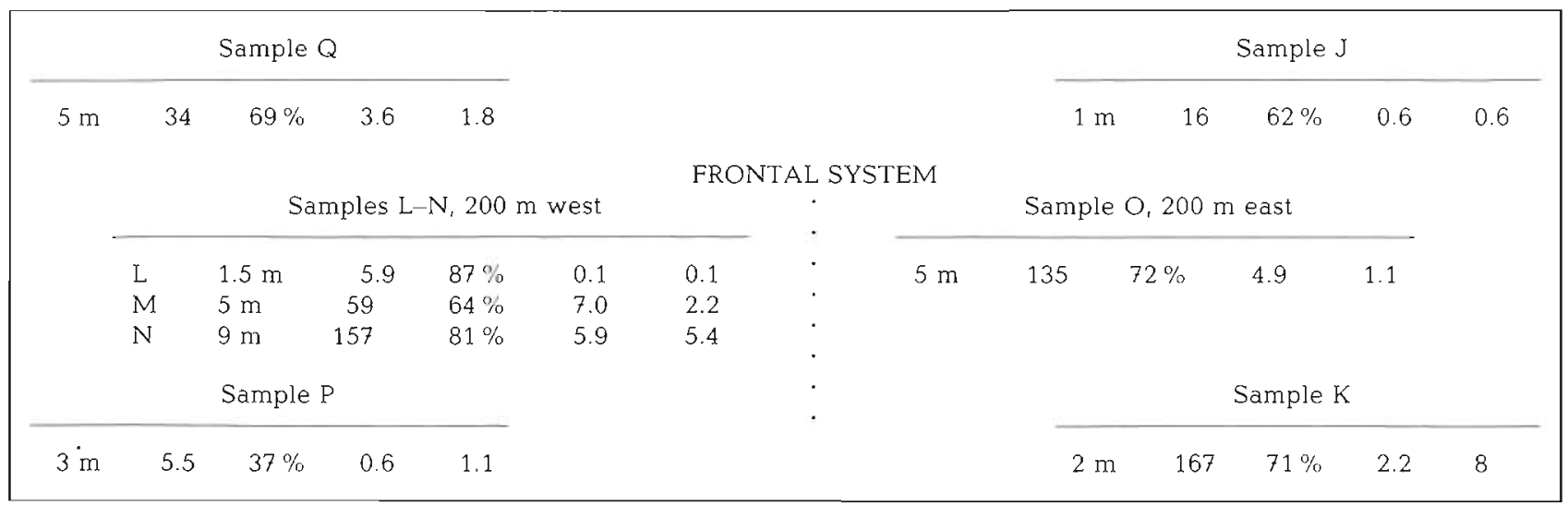




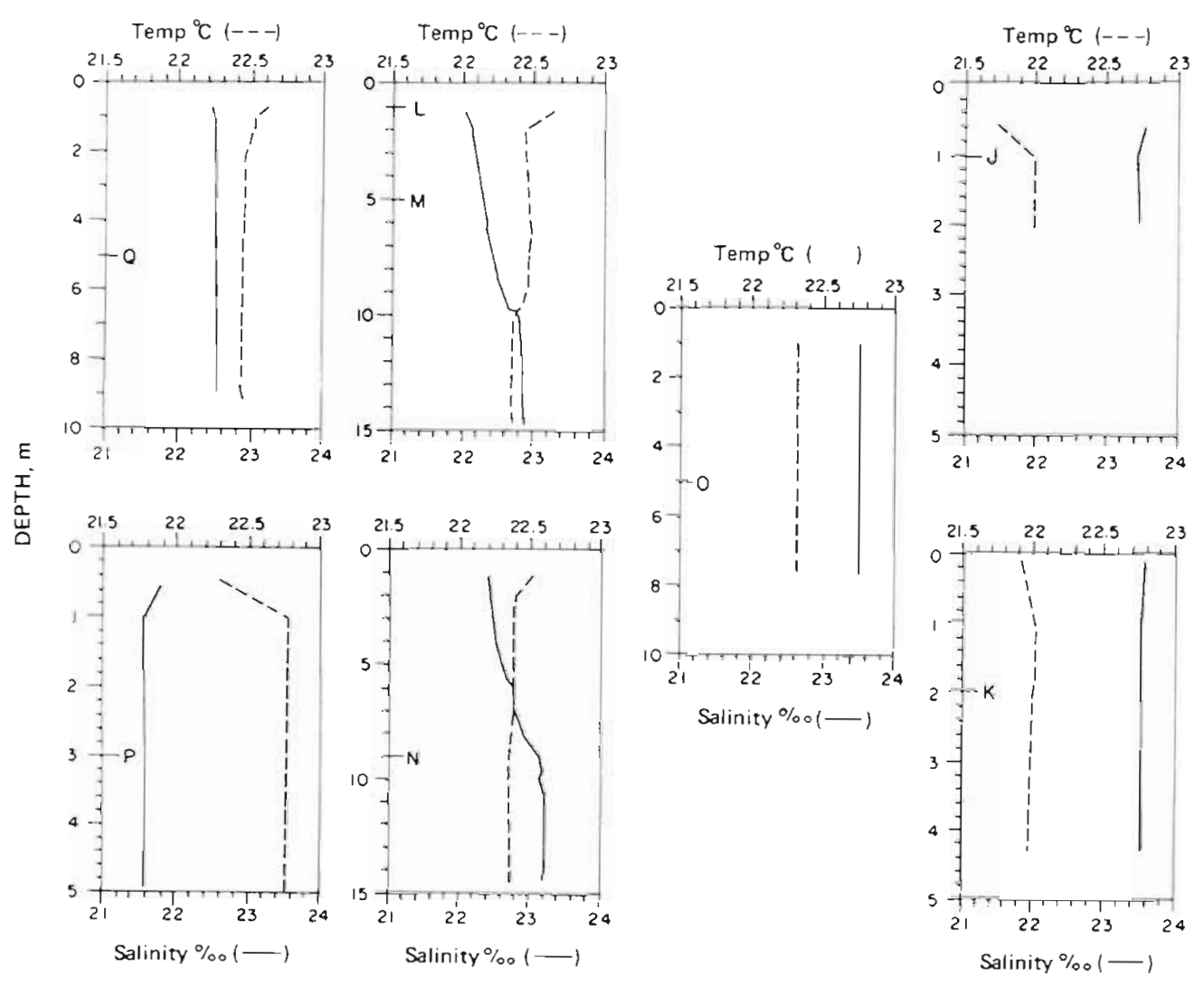

19 SEPT 1985

Fig. 5. Temperature $\left({ }^{\circ} \mathrm{C}\right)$ and salinity $(\%)$ profiles for water column at collection sites of Samples J to Q inclusive, 19 Sep 1985. Depths of samples indicated by corresponding letter on the figure. The surface frontal feature is between Samples L-N (west of front) and $O$ (east of front). For site locations see Fig. 2

repositioned closer to the front and a further temperature-salinity profile recorded - that illustrated for Sample N. Note that during the intervening period (66 min) the salinity of the water column had increased uniformly by 0.3 to $0.4 \%$ throughout its entire depth yet the shape of the profile changed very little. This observation supports the earlier description by Kuo et al. (in press) of the frontal system as a progressive feature, rather than being a boundary of fixed salinity, at which salinity may increase as flood tide progresses. The 0.3 to $0.4 \%$ uniform increase in salinity seen at the fixed position corresponding to sampling sites $\mathrm{L}$ through $\mathrm{N}$ simply reflects the progression of the front with the flood tide. Temperature and salinity characteristics at the site of Sample $\mathrm{O}\left(22.3^{\circ} \mathrm{C}, 23.5 \%\right)$ were similar to $\mathrm{N}\left(22.3^{\circ} \mathrm{C}, 23.2 \%\right)$ but of higher salinity, even allowing for the 0.3 to $0.4 \%$ temporal salinity change described earlier, than $M\left(22.4^{\circ} \mathrm{C}, 22.3 \%\right)$ and $\mathrm{L}$ $\left(22.7^{\circ} \mathrm{C}, 22 \%\right)$. The physical and biological data collected for Samples L, M, N and $\mathrm{O}$ are in close agreement in supporting a suggestion of water plunging to depth as it flows from east to west across the frontal system.
Samples collected near the James River Bridge on 19 September ( $P$ and $Q$ ) had low concentrations of $<150 \mu \mathrm{m}$ larvae, especially so for Sample $\mathrm{P}$ on the south side of the River (Tables 1 and 3). In Sample $P$ oyster larvae of $>150 \mu \mathrm{m}$ represented $31 \%$ of the total larvae, a markedly high percentage compared to all other samples and higher than the $16 \%$ by number of oyster larvae of $>150 \mu \mathrm{m}$ recorded in Sample $Q$ (Table 3).

Sample $Q$ was originally intended to characterize freshwater, downstream-flowing water on the north bank of the river prior to its convergence with the frontal system. As such the data for Sample $Q$ was expected to be comparable to Sample $L_{i}$ however. Table 3 clearly illustrates a difference between $Q$ and $\mathrm{L}$. The reason for this difference lies partly in the sampling regime used. Temperature and salinity profiles collected at the sampling site for $Q$ suggested that the water was well mixed, at least below $2 \mathrm{~m}$ (Fig. 5). The sample was taken at $5 \mathrm{~m}$. In fact, the temperature and salinity values for $\mathrm{Q}\left(22.45^{\circ} \mathrm{C}, 22.6 \%\right)$ are intermediate between those of $\mathrm{M}$ and $N$ (Fig. 5) suggesting that $Q$ sampled a mixture of upstream-flowing high 
salinity water containing a high proportion of $>150 \mu \mathrm{m}$ oyster larvae (Table 3) and fresher, downstream-flowing water. Note also that the sampling regime assumes vertically homogenous distribution of larvae in the water column. Results of larval behaviour experiments, described later in this report, suggest strongly oriented upward swimming by smaller $(<160 \mu \mathrm{m})$ larvae. If indeed such larvae exhibit net surfaceward motion and aggregation at the site of Sample $Q$ (perhaps in the warmer surface layer of $2 \mathrm{~m}$ depth), then an elevated percentage of larger larvae, when compared to a truly homogenous water column, would be found at $Q$, as in fact was the case. Sample $P$, like $Q$, was taken from an apparently well-mixed water column (Fig. 5); however, salinity at this site was considerably lower than all other sample sites for that date.

Plankton sampling on 20 September was effected at 4 sample sites; on Hampton Flats in $1 \mathrm{~m}(\mathrm{X}), 200 \mathrm{~m}$ to the east $(R, S)$ and west $(T, U, V)$ respectively of the front. and on the northern side of the James in the vicinity of the James River Bridge (W) (Fig. 2). Samples X and S, both of which were collected at a depth of $2 \mathrm{~m}$ to the east of the front, exhibited relatively low total numbers of larvae per $100 \mathrm{l}$, comparable percentages of $<150 \mu \mathrm{m}$ length fractions and comparable number of oyster larvae of $>150 \mu \mathrm{m}$ length (Table 4 ). Of special note is the greater number of $>250 \mu \mathrm{m}$ oyster larvae than 150 to $250 \mu \mathrm{m}$ larvae in both collections. Sample $\mathrm{R}$, the $7 \mathrm{~m}$ collection taken $200 \mathrm{~m}$ east of the front had, by comparison, higher absolute numbers of larvae and percentage of $<150 \mu \mathrm{m}$ larvae. Oyster larvae $>150 \mu \mathrm{m}$ were comparable in number to those at shallower depth but the 150 to $250 \mu \mathrm{m}$ size range predominated (Table 4 ).

To the west of the frontal system at $2 \mathrm{~m}$ depth (T) a relatively low number of larvae per $100 \mathrm{l}$ was again evident; however, these were predominantly $<150 \mu \mathrm{m}$ in length and oyster larvae of $>150 \mu \mathrm{m}$ length were almost absent (Table 4). Clearly, the composition of larvae in Samples $\mathrm{T}$ and $\mathrm{S}$, at equal depth but on opposite sides of the front, were markedly different. On 20 September larval sampling was effected in conjunction with a dye release study of the type described in detail in Kuo et al. (in press). A $4 \%$ solution of Rhodamine WT dye was released at the surface downstream (to the east) of the front. Dye moved to the front at the surface then plunged to be recorded at depths of 5 to $9 \mathrm{~m}$ upstream (west) of the front (for accompanying temperature and salinity data, see Fig.6). Consequently larval collection for Samples $\mathrm{U}$ and $\mathrm{V}$ was effected at 5 and $9 \mathrm{~m}$ respectively. At U only 20 larvae per 1001 were observed, a value between that recorded for samples $S$ and $X$ to the east of the front. The similarity between Samples U, S and X in terms of total larvae per 1001 , the low percentage of $<150 \mu \mathrm{m}$ larvae and the proponderance of $<250 \mu \mathrm{m}$ larvae in the $<150 \mu \mathrm{m}$ fraction (Table 4) again support the contention that larvae are, like dye, transported passively at the frontal system. Sample $V$, collected at $9 \mathrm{~m}$ depth to the west of the front, closely resembled Sample $\mathrm{R}$, collected at $7 \mathrm{~m}$ depth to the east of the front, in terms of suggesting continuity from $\mathrm{R}$ to $\mathrm{V}$ (Table 4 ).

Upstream of the frontal system near the James River Bridge 31 larvae per 1001 were recorded in Sample W. Although the $<150 \mu \mathrm{m}$ larvae comprised a smaller percentage of this total (71\%) than at $\mathrm{T}(89 \%)$, this percentage was still notably higher than in Samples $U$, $\mathrm{S}$ and $\mathrm{X}(34,61$ and $59 \%$ respectively; Table 4$)$ suggesting stronger continuity between Samples $W$ and $T$ than $X, S, U$ and $W$; however, the occurrence of mixing of upstream-flowing bottom water with downstreamflowing water at the collection site of Sample $Q$ on the previous day (19 Sep) has already been discussed and should be reiterated here in that $W$ and $Q$ occupy the same geographical location (Samples $W$ and $Q$ were not, however, occupied on exactly the same state of tide). The aforementioned 'mixing' may well provide explanation for the presence of greater numbers of $>150 \mu \mathrm{m}$ oyster larvae in Sample $\mathrm{W}$ than in $\mathrm{T}$.

In summary each day of field sampling examined a slightly different aspect of larval distribution with respect to the frontal system. The results generally support the contention that bivalve larvae are passively transported from east to west, past the surface manifestation of the front, and plunge to depth as the more

Table 4. Characterization of plankton samples for 20 September. Data display as for Table 2. For sites of sample collections see Fig. 2

\begin{tabular}{|c|c|c|c|c|c|c|c|c|c|c|c|c|c|}
\hline \multicolumn{5}{|c|}{ Sample W } & & & & & \multicolumn{5}{|c|}{ Sample X } \\
\hline $1 \mathrm{~m}$ & 31 & $71 \%$ & 2.6 & & & & & & $1 \mathrm{~m}$ & 14 & $59 \%$ & 0.7 & 2.1 \\
\hline \multicolumn{9}{|c|}{ Samples T-V, $200 \mathrm{~m}$ west } & \multicolumn{4}{|c|}{ Samples R-S, 200 m east } & \\
\hline $\mathrm{T}$ & $2 \mathrm{~m}$ & 28 & $89 \%$ & 0.3 & 0 & . & S & $2 \mathrm{~m}$ & 31 & $61 \%$ & 1.5 & 2 & \\
\hline U & $5 \mathrm{~m}$ & 20 & $34 \%$ & 0.8 & 4.6 & $\cdot$ & $\mathrm{R}$ & $7 \mathrm{~m}$ & 105 & $90 \%$ & 1.9 & 1.3 & \\
\hline V & $9 \mathrm{~m}$ & 131 & $83 \%$ & 6.1 & 1.3 & $\dot{.}$ & & & & & & & \\
\hline
\end{tabular}




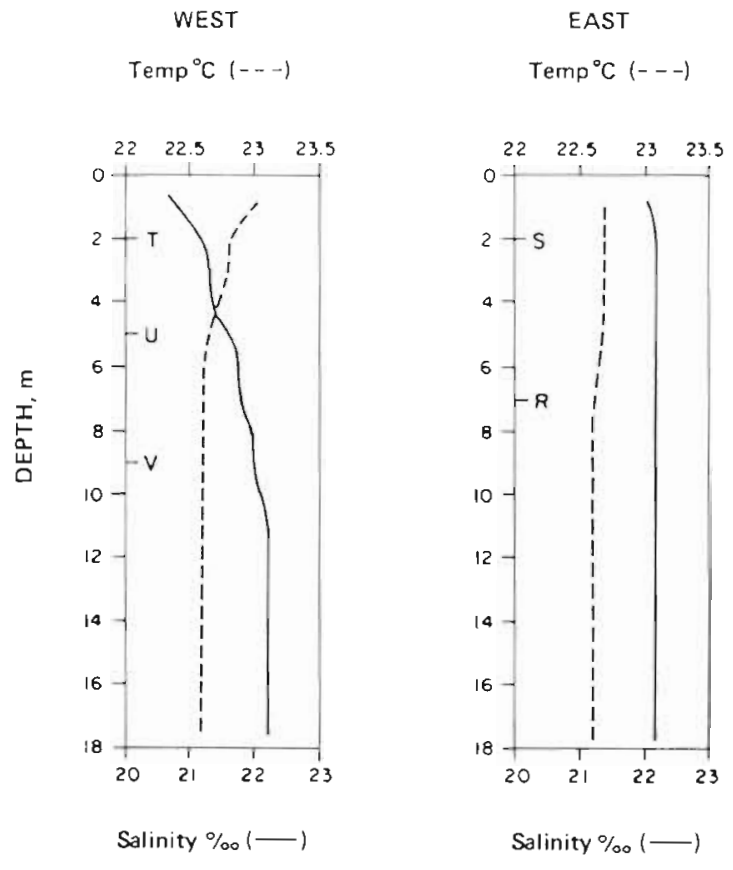

20 SEPT 1985

Fig. 6. Temperature $\left({ }^{\circ} \mathrm{C}\right)$ and salinity $(\%)$ profiles for water column at collection sites of Samples $\mathrm{R}$ to $\mathrm{V}$ inclusive, 20 Sep 1985. Depths of samples indicated by corresponding letter on the figure. The surface frontal feature lies between. Samples $\mathrm{T}-\mathrm{V}$ (west of front) and S-R (east of front). For site locations see Fig. 2

saline water in which they are contained encounters downstream-flowing (west to east) less saline water. The results further suggest that passive transport continues, at least in part, as the more saline water continues to travel upstream west of the front towards the James River Bridge. Immediately upstream of the front surface water on the northerly shore of the James is characterized by the consistent absence of larger larvae suggesting that the smaller larvae present result from either recent spawnings in the James and/or upward movement of larvae previously transported through the frontal system. At a distance upstream of the front, in the vicinity of sampling sites $Q$ and $W$, dispersal of bivalve larvae, including oyster larvae, probably results from both passive movement, including that associated with mixing of upstream- and downstream-flowing waters, and active depth regulation through swimming.

\section{Laboratory studies}

Larval swimming was examined in 3 size ranges of larvae from 3 different larval cultures (Table 5). The first shelled ' $D$ ' or straight hinge stage larvae corre- spond to ca $24 \mathrm{~h}$ post-fertilization and the $<150 \mu \mathrm{m}$ stage of the field plankton samples, whereas 'umbo' stage larvae correspond to the $>150 \mu \mathrm{m}$ length fraction. Both stages readily swam through the $3 \%$ salinity interface. At a mean swimming velocity of $0.37 \mathrm{~mm} \mathrm{~s}^{-1}$, ' $\mathrm{D}$ ' larvae can ascend through a $5 \mathrm{~m}$ water column in $3 \mathrm{~h}$ 45 min, 'umbo' larvae require between $1 \mathrm{~h} 25 \mathrm{~min}$ and $1 \mathrm{~h} 55 \mathrm{~min}$. Clearly, both of these larval stages can ascend through a significant portion of the water column in the James River in the time interval corresponding to one flood or ebb tide. Pediveliger stage larvae are competent to settle and have both a velum (swimming organ) and a foot (for crawling). No observations were made of pediveliger larvae swimming through the salinity interface, irrespective of the presence and absence of oriented light or food. Pediveliger larval swimming was restricted to small $(<5 \mathrm{~cm})$ but frequent excursions from the chamber bottom. Due to the 'bouncing' nature of the swimming behaviour no ecological meaningful measurements of swimming speed could be made. These results suggest that such larvae do not seek to regulate depth in the midst of the water column but, rather, remain near the sedimentwater interface.

\section{DISCUSSION}

Three specific questions were posed in this study: Are there bivalve larvae in the water masses converging on the frontal system? Are these larvae passively transported through the frontal system? Will larval swimming influence their final position in the water column after transport through the front? The answer to all 3 questions is yes. The field observations of flow, salinity, temperature, dye tracer and bivalve larval distributions on both sides of the front support the hypothesis that the transient frontal system is responsible for the injection of surface water and associated larvae into deeper, upstream-flowing water during flood tide. Active depth regulation by bivalve larvae is of little consequence during the short period of passage through the frontal system in that water flow velocities, often exceeding $50 \mathrm{~cm} \mathrm{~s}^{-1}$ in surface waters approaching and immediately to the east of the front, are over 2 orders of magnitude higher than the highest rates of vertical displacement (0.37 to $1.02 \mathrm{mms}^{-1}$ ) recorded for oyster larvae in the laboratory. Once the frontal system is passed, active depth regulation can, by contrast, be pivotal in determining the position of the larvae in the water column and, therefore, their eventual transport upstream or downstream. Even the smallest veliger larvae appear capable of swimming through the depth of the water column in the James in one tidal excursion. Field 
Table 5. Larval swimming behaviour in laboratory systems. n: number of data points. Velocity is rate of vertical movement (see text). Time for $5 \mathrm{~m}$ is estimate of time to ascend through $5 \mathrm{~m}$ when swimming continuously. 'Cross $3 \%$ ' describes if larvae did or did not swim through salinity interface

\begin{tabular}{|c|c|c|c|c|c|c|c|c|c|c|}
\hline $\begin{array}{l}\text { Larval } \\
\text { stage }\end{array}$ & $\begin{array}{l}\text { Length } \\
(\mu \mathrm{m})\end{array}$ & $\begin{array}{l}\mathrm{SD} \\
(\operatorname{um})\end{array}$ & $\begin{array}{c}95 \% \mathrm{Cl} \\
(\mu \mathrm{m})\end{array}$ & $n$ & $\begin{array}{l}\text { Velocity } \\
\left(\mathrm{mm} \mathrm{s}^{-1}\right)\end{array}$ & $\begin{array}{c}\mathrm{SD} \\
\left(\mathrm{mm} \mathrm{s}^{-1}\right)\end{array}$ & $\begin{array}{l}95 \% \mathrm{CI} \\
\left(\mathrm{mm} \mathrm{s}^{-1}\right)\end{array}$ & $n$ & $\begin{array}{c}\text { Time } \\
\text { for } 5 \mathrm{~m}\end{array}$ & $\begin{array}{c}\text { Cross } \\
3 \%\end{array}$ \\
\hline \multicolumn{11}{|c|}{$29 \mathrm{~cm}$ chamber } \\
\hline D & 75.0 & 4.7 & 1.68 & 30 & 0.37 & 0.80 & 0.12 & 170 & $3 \mathrm{~h} 45 \mathrm{~min}$ & Yes \\
\hline Umbo & 157.5 & 15.9 & 5.68 & 30 & 1.02 & 2.01 & 0.09 & 120 & $1 \mathrm{~h} 25 \mathrm{~min}$ & Yes \\
\hline \multicolumn{11}{|c|}{$59 \mathrm{~cm}$ chamber } \\
\hline Umbo & 159.9 & 18.4 & 6.58 & 30 & 0.72 & 1.26 & 0.31 & 63 & $1 \mathrm{~h} 55 \mathrm{~min}$ & Yes \\
\hline Pediv. & 317.2 & 13.3 & 4.74 & 30 & \multicolumn{5}{|c|}{ 'Bouncing behaviour' - see text } & No \\
\hline
\end{tabular}

observations of abundant smaller larvae in ebbing surface water immediately upstream of the surface frontal feature may, in part, be due to lack of upward swimming of larger larvae from deeper water upstream of the front.

The continued transport of larvae in an upstream direction is dependent on their retention in the more saline bottom water of the James. A review of factors influencing active depth regulation is appropriate. Planktonic bivalve larvae can swim in the vertical plane in either a helical pattern (Bayne 1964, 1976, Cragg 1980) or in straight lines while rotating on their axis. Swimming activity has been demonstrated in response to gravity, light (both wavelength and intensity), temperature, salinity and pressure. In order to understand dispersal processes behavioural data are required in terms of taxis, rate, and the hierarchical values of these stimuli. Does light, for instance, override salinity? The cursory examination reported here for Crassostrea virginica suggests not, but this might not apply to all developmental stages of this or other species. General reviews addressing the distribution or motile behaviour of planktonic organisms have been made with respect to pressure (Knight-Jones \& Morgan 1966, Flugel 1972, Naylor \& Atkinson 1972), light (Spooner 1933, Clarke \& Denton 1962, Thorson 1964, Clarke 1970) and salinity or temperature interfaces (Harder 1968). Mileikovsky (1973) reviewed the 'speed' of active movement of a number of pelagic larvae of marine bottom invertebrates and concluded, as I have for the present study, that these were adequate to allow depth regulation in nearshore and estuarine waters including those with strong tidal currents. Data relating to bivalve larvae are summarized in Cragg (1980), Mann \& Wolf (1983) and Mann (1986a). These authors support the concept of active depth regulation by larvae of a variety of bivalve species; however, the nature of these responses is not always consistent between species or even throughout larval development of a single species. Depth regulation is effected by the combination of upward swimming with passive or actively regulated sinking.
A variety of opinions exist as to the role of active depth regulation in the retention of bivalve larvae in estuarine and shallow coastal systems. The works of J. Nelson (1911), T. C. Nelson (1953, 1955), Carriker (1951, 1961), Kunkle (1957), Haskin (1964), and Wood \& Hargis (1971) suggest that bivalve larval retention and/or net upstream transport in estuarine systems may be a combination of both active and passive processes. The active component consists of either a tidally synchronised, cyclical rising and sinking of larvae, at or near the level of no net motion, or depth regulation irrespective of tidal state. These authors viewpoint is supported by similar comments with respect to the larvae of barnacles (Bousfield 1955), fish (Fortier \& Leggett 1983), brachyuran crabs (see contributions in Kennedy 1982; Sulkin 1984) and even dinoflagellates (Tyler \& Seliger 1978, 1981). Quayle (1952) examined vertical distribution of Venerupis pullastra (Montagu) larvae in Scottish coastal waters and concluded that they perform active diel migrations, being near the surface at night and at certain tidal phases, and nearer the bottom in the daytime. By contrast Korringa (1952) suggests that larvae are predominantly passive drifters. Andrews $(1979,1983)$, suggests that, although larvae may be continuous swimmers with the ability to regulate depth, there is little need to invoke active depth selection to explain retention in locations where vertical density stratification is small. Andrews (1983, Tables 1 and 2 respectively) presents data for total bivalve larvae collected at Brown Shoal and oyster larvae collected at Wreck Shoal in the James River (Fig. 1) over a tidal cycle and at various depths in the water column. His data demonstrate the presence of bivalve larvae and oyster larvae of $<200 \mu \mathrm{m}$ length at all sampled depths throughout the tidal cycle; however, both Brown Shoal and Wreck Shoal are upstream of the James River Bridge and therefore some distance from the frontal system examined in this study. Boicourt (1982) and Seliger et al. (1982) present data and arguments which explain observed differences in bivalve recruitment in adjacent tributaries of the lower Choptank River (Chesapeake Bay) purely in terms of differ- 
ences in hydrography. Similarly, de Wolf $(1973,1974)$ explains retention of barnacle larvae in estuaries by purely passive means. The paucity of the understanding of ecology of bivalve larvae is underscored by the fact that both Carriker (1951) and Korringa (1952) were able to interpret one data set, that of Carriker (1951), to support differing viewpoints; and that Andrews (1979, 1983) could present a series of data collected at the same time and locale, the James River, as that reported by Wood \& Hargis (1971) with, again, each author or authors giving a somewhat different interpretation of the factors responsible for their conclusions. In the present study there is little doubt that transport through the frontal system is passive; however, the relative roles of passive and active movement in determining subsequent dispersal of the larvae is less obvious.

Despite the dichotomy of opinion on field data the experiments of Nelson \& Perkins (1931), Haskin (1964), and Hidu \& Haskin (1978) clearly support the interpretation of field observations of NeIson (1911), Carriker (1951), Nelson (1953, 1955) and Kunkle (1957) with respect to active depth regulation. Mann (1986b) examined the value of laboratory experiments by using only laboratory-generated behavioural data in concert with field-collected physical data to develop a numerical predictive model of occurrence of Arctica islandica larvae on the Southern New England Shelf. The model, developed using data from Lutz et al. (1982), Mann (1982) and Mann \& Wolf (1983), was compared to field observations (Mann 1985) and exhibited good agreement during a period of seasonal thermal stratification; however, this agreement disappeared as vertical mixing of the water column became more intense. The value of laboratory experiments appears to be dependent on the stability of stratification, a function that is both site- and time-specific. Clearly, experiments are needed to examine the point at which active depth regulation is overcome by intense physical processes to become passive movement.

In an estuarine environment like the James River, where a relatively small change in depth may result in significant changes in salinity, temperature, and both velocity and direction of movement (Pritchard 1951. 1952, Kuo et al. in press), great sensitivity in depth regulation would be of significant selective advantage in influencing horizontal dispersal. Sensitivity of depth regulation in bivalve larvae is discussed by Cragg (1980), Mann \& Wolf (1983) and Mann (1986a) who note that larvae of estuarine species such as Mercenaria mercenaria (data from Haskin 1964) and Ostrea edulis L. (data from Cragg \& Gruffydd 1975) have greater sensitivity to pressure than either Mytilus edulis L. (data from Bayne 1963) or Arctica islandica (data from Mann \& Wolf 1983), and that all appear more sensitive than the larvae of Pecten maximus $L$. (data from Cragg, 1980). These data, although limited, support the hypothesis of decreasing sensitivity in depth regulation with increasing absolute depth and depth range of occurrence of the adult form. Such a hypothesis suggests that Crassostrea virginica larvae would have very sensitive depth-regulatory capabilities, capabilities that could be used to advantage in the James and similar estuarine environments.

Larval samples in the field collections were arbitrarily assigned to 1 of 3 size classes by length (maximum dimension) : $<150 \mu \mathrm{m}, 150$ to $250 \mu \mathrm{m},>250 \mu \mathrm{m}$. Precise aging of these size classes has obvious value in estimating the residence time of the larvae in the plankton since spawning and time remaining prior to settlement. Davis \& Calabrese (1964) estimate optimum temperature and salinity conditions for survival and growth of Crassostrea virginica larvae to be above $30^{\circ} \mathrm{C}$ and between 18 and $35 \%$. Under these conditions larvae reach metamorphic competency 275 to $315 \mu \mathrm{m}$, corresponding approximately to the $>250 \mu \mathrm{m}$ size fraction examined here) in 10 to $12 \mathrm{~d}$. In the present field study salinities were within the lower half of this optimal range; however, temperatures were predominantly in the 20 to $25^{\circ} \mathrm{C}$ range. Under these conditions newly formed straight hinge larvae (ca $80 \mu \mathrm{m}$ in maximum dimension) will still be less than $150 \mu \mathrm{m}$ length at $8 \mathrm{~d}$ old. Davis \& Calabrese note that time to first settlement at $27.0 \%$ salinity increases from 14 to $16 \mathrm{~d}$ at $27.5^{\circ} \mathrm{C}$ to between 28 and $30 \mathrm{~d}$ at $22^{\circ} \mathrm{C}$. Given these values it is probable that the 150 to $250 \mu \mathrm{m}$ length fraction from the plankton includes larvae that are 12 to $24 \mathrm{~d}$ old while the $>250 \mu \mathrm{m}$ fraction may be older still. Caution is required when making estimates of age from length: in being dispersed throughout the James River basin oyster larvae encounter continually changing temperature and salinity. Also, Davis \& Calabrese' estimates are based on growth with cultured algal foods however, we have only a marginal understanding of how natural food quality and quantity varies in the field. Major oyster settlement in the James is observed in the vicinity of Wreck Shoal (Fig. 1), some $20 \mathrm{~km}$ upstream of the frontal system off Newport News Point. A mean velocity in bottom water of $10 \mathrm{~cm} \mathrm{~s}^{-1}$ would enable transport of larvae from the frontal system to Wreck Shoal in $2 \frac{1}{2} \mathrm{~d}$, a short period compared to the estimated duration of larval developmental under the prevailing conditions: however, information on bottom current velocities is poor, and improved knowledge of current velocities in this water is clearly desirable.

Acknowledgements. I thank Robert J. Byrne, Evon P Ruzecki, Albert Y Kuo, John M. Brubaker, and John E Olney for much useful discussion. The manuscript was improved by critical reviews by Jay D. Andrews Michael Castagna, George C. Grant, William J. Hargis Jr. and Evon P. Ruzecki. 


\section{LITERATURE CITED}

Andrews, J. D. (1951). Seasonal patterns of oyster setting in the James River and Chesapeake Bay. Ecology 32: $752-758$

Andrews, J. D. (1954). Setting of oysters in Virginia. Proc. natl Shellfish Ass. 45: 38-46

Andrews, J. D. (1979). Pelecypoda: Ostreidae. In: Giese, A. C., Pearse, J. S. (eds.) Reproduction of marine invertebrates, Vol. 5: pelecypods and lesser classes. Academic Press, New York, p. 293-339

Andrews, J. D. (1982). The James River public seed oyster area in Virginia. Va Inst. Mar Sci. Spec. Rep. Appl. Mar. Sci. Ocean Eng. No. 261, p. 1-60

Andrews, J. D. (1983). Transport of bivalve larvae in James River, Virginia. J. Shellfish Res. 3: 29-49

Baylor, J. B. (1894). Method of defining and locating natural oyster beds, rocks, and shoals. Oyster Records (pamphlets, one for each Tidewater, $\mathrm{Va}$, county, that listed the precise boundaries of the Baylor survey). Board of Fisheries of Virginia. Va Inst. Mar. Sci., Gloucester Point, Va, USA

Bayne, B. L. (1963). Responses of Mytilus edulis larvae to increase in hydrostatic pressure. Nature, Lond. 198: 406-407

Bayne, B. L. (1964). The responses of the larvae of Mytilus edulis L. to light and to gravity. Oikos 15: 162-174

Bayne, B. L. (1976). Marine mussels: their ecology and physiology. Cambridge University Press, Cambridge

Boicourt, W. C. (1982). Estuarine larval retention mechanisms on two scales. In: Kennedy, V S. (ed.) Estuarine comparisons. Academic Press, New York, p. 445-457

Bousfield, E. L. (1955). Ecological control of the occurrence of barnacles in the Miramichi estuary. Bull. natn. Mus. Can 137: $1-69$

Byrne, R. J., Kuo, A. Y., Mann, R., Brubaker, J. M., Ruzecki, E. P., Hyer, P. V., Diaz, R. J., Posenau, J. H. (1987). New Port Island: an evaluation of potential impacts on marine resources of the lower James River and Hampton Roads. Va. Inst. Mar. Sci. Spec. Rep. Appl. Mar. Sci. Ocean Eng. No. 283: p. $1-271$

Carriker, M. R. (1951). Ecological observations on the distribution of oyster larvae in New Jersey estuaries. Ecol. Monogr 21: 19-38

Carriker, M. R. (1961). Interrelation of functional morphology, behaviour and autecology in early stages of the bivalve Mercenaria mercenaria. J. Elisha Mitchell scient. Soc. 177: $168-242$

Castagna, M., Kraeuter, J. N. (1981). Manual for growing the hard clam Mercenaria mercenaria. Va Inst. Mar. Sci. Spec. Rep. Appl. Mar. Sci. Ocean Eng. No. 249, p. 1-110

Chanley, P., Andrews, J. D. (1971). Aids for identification of bivalve larvae of Virginia. Malacologia 11: 45-119

Clarke, G. L. (1970). Light conditions in the sea in relation to the diurnal vertical migrations of animals. In: Farquhar, G. B. (ed.) Proceedings of an international symposium on biological sound scattering in the ocean. Maury Center for Ocean Science, Department of the Navy, Washington, D.C., p. 41-50

Clarke, G. L., Denton, E. J. (1962). Light and animal life. In: Hill, M. N. (ed.) The sea. Interscience Publishers, New York, p. $456-468$

Cragg, S. M. (1980). Swimming behaviour of the larvae of Pecten maximus (L.) (Bivalvia). J. mar. biol. Ass. U.K. 60: 551-564

Cragg, S. M., Gruffydd, L. D. (1975). The swimming behaviour and the pressure responses of the veliconcha larvae of Ostrea edulis (L.). In: Barnes, H. (ed.) Proceedings of the
Ninth European Marine Biology Symposium, Oban, Scotland, 1974. Aberdeen University Press, Aberdeen, p. $43-57$

Davis, H. C., Calabrese, A. (1964). Combined effects of temperature and salinity on development of eggs and growth of larvae of $M$. mercenaria and $C$. virginica. U.S. Fish. Wildl. Serv. Fish. Bull. 63: 643-655

Flugel, H. (1972). Pressure - animals. In: Kinne, O. (ed.) Marine ecology, Vol. 1, Part 3. Wiley-Interscience, New York, p. 1407-1450

Fortier, L., Leggett, $W$ C. (1983). Vertical migrations and transport of larval fish in a partially mixed estuary. Can. J. Fish. Aquat. Sci. 40: 1543-1555

Harder, W (1968). Reactions of plankton organisms to water stratification. Limnol. Oceanogr 13: 156-160

Haskin, H. H. (1964). The distribution of oyster larvae. In: Marshall, N., Jeffries, H. P., Napora, T. A., Sieburth, J. M. (eds.) Symposium on experimental marine ecology, Graduate School of Oceanography, University of Rhode Island. Occ. Publ. 2: 76-80

Haven, D. S., Fritz, L. W. (1985). Setting of the American oyster Crassostrea virginica in the James River, Virginia, USA: temporal and spatial distribution. Mar. Biol. 86: 271-282

Haven, D. S. "Hargis, W. J., Jr, Kendall, P. (1981a). The oyster industry of Virginia: its status, problems and promise 1981 (revised) Va Inst. Mar. Sci., Spec. Paper Mar. Sci. No 4: $1024 \mathrm{p}$.

Haven, D. S., Whitcomb, J. P. (1983). The origin and extent of oyster reefs in the James River, Virginia. J. Shellfish. Res. 3: $141-151$

Haven, D. S., Whitcomb, J. P., Kendall, P. (1981b). The present and potential productivity of the Baylor Grounds in Virginia. Va Inst. Mar. Sci. Spec. Rep. Appl. Mar Sci. Ocean Eng. No. 243: p. 1-154

Hidu, H., Haskin, H. H. (1978). Swimming speeds of oyster larvae Crassostrea virginica in different salinities and temperatures. Estuaries 1: 252-255

Kennedy, V S. (ed.) (1982). Estuarine comparisons. Academic Press, New York

Knight-Jones, E. W., Morgan, E. (1966). Responses of marine animals to changes in hydrostatic pressure. Oceanogr mar Biol. A. Rev. 4: 267-299

Korringa, P. (1952). Recent advances in oyster biology. Q. Rev. Biol. 27: 266-308 \& 339-365

Kuo, A. Y., Byrne, R. J., Brubaker, J. M., Posenau, J. H. (in press). Vertical transport across an estuary front. In: Dronkers, J., Van Leussen, W (eds.) Physical processes in estuaries. Springer Verlag, Berlin and New York

Kunkle, D. E. (1957). The vertical distribution of larvae in Delaware Bay. Proc. natl Shellfish. Ass. 48: 90-91

Loosanoff, V. L. (1932). Observations on propogation of oysters in James and Corrotoman Rivers and the sea side of Virginia. Report of the Virginia Commission Fisheries, Newport News, Va, USA

Lutz, R. A., Mann, R., Goodsell, J. G., Castagna, M. (1982). Larval and early post larval development of the Ocean Quahog Arctica islandica. J. mar. biol. Ass. U.K. 62: 745-769

Mann, R. (1982). The seasonal cycle of gonad development in Arctica islandica on the Southern New England shelf. Fish. Bull. U.S. 80 (2): 315-326

Mann, R. (1985). Seasonal changes in the depth distribution of bivalve larvae on the Southern New England shelf. J. Shellfish Res. 5: 57-64

Mann, R. (1986a). Sampling of bivalve larvae. In: Jamieson, G. S., Bourne, N. (eds.) North Pacific workshop on stock 
assessment and management of invertebrates. Can. Spec. Publ. Fish. Aquat. Sci. 92: 107-116

Mann, R. (1986b). Arctica islandica (Linne) Iarvae: active depth regulators or passive particles. Am. Malac. Bull. Spec. Ed. No. 3: 51-57

Mann, R., Wolf, C. C. (1983). Swimming behaviour of larvae of the ocean quahog Arctica islandica in response to pressure and temperature. Mar. Ecol. Prog. Ser 13: 211-218

Mileikovsky, S. A. (1973). Speed of active movement of pelagic larvae of marine bottom invertebrates and their ability to regulate their vertical position. Mar. Biol. 23: $11-17$

Moore, H. F. (1911). Condition and extent of the oyster beds in the James River, Virginia. U.S. Bur Fish. Doc. No. 729: $1-83$

Naylor, E., Atkinson, R. J. A. (1972). Pressure and the rhythmic behaviour of inshore marine animals. Symp. Soc. exp. Biol. 26: $395-415$

Nelson, J. (1911). Report of the biologist. Rep. New Jers. St. agric. Exp. Stn, June 1910, p. 183-218

Nelson, T C. (1953). Some observations on the migrations and setting of oyster larvae. Proc. natl Shellfish. Ass. 43: 99-104

Nelson, I C. (1955). Observations on the behaviour and distribution of oyster larvae. Proc. natl Shellfish Ass. 45: $23-28$

Nelson, T. C., Perkins, E. B. (1931). Annual report of the Department of Biology for the year ending June 30, 1930. N. J. agric. Exp. Stn Bull. 522: 1-47

Pritchard, D. W. (1951). The physical hydrography of estuaries and some applications to biological problems. Trans. N. Am. WildL Conf. 16: 368-376

Pritchard, D. W. (1952). Distribution of oyster larvae in relation to hydrographic conditions. Proc. Gulf Caribb. Fish. Inst. Nov. 1952, p. 1-10

Quayle, D. B. (1952). Structure and biology of the larva and spat of Venerupis pullastra (Montagu). Trans. R. Soc. Edinb. 62: 255-297

Ruzecki, E. P., Moncure, R. W (1969). Dye distribution results from point release in the James River model. In: Hargis, W. J., Jr (ed.) Utilization of physical and mathematical models in marine resources research, planning and man- agement. A report for the period Sept. 1967 - Dec. 1968 Va Inst. Mar. Sci., p. 1-22

Ruzecki, E. P., Hargis, W. J., Jr (in press). Interaction between circulation of estuary of the James River and transport of oyster larvae. In: Neilson, B., Kuo, A. Y., Brubaker, J. M. (eds.) Estuarine circulation. Humana Press, Clifton, New Jersey

Seliger, H. H., Boggs, J. A., Rivkin, R. B., Biggley, W H. Aspden, K. R. H. (1982). The transport of oyster larvae in an estuary. Mar. Biol. 71: 57-72

Spooner, G. M. (1933). Observations on the reactions of marine plankton to light. J. mar. biol. Ass. U.K. 19: $385-438$

Sulkin, S. D. (1984). Behavioural basis of depth regulation of the larvae of brachyuran crabs. Mar. Ecol. Prog. Ser. 15 $818-205$

Taggart, C. T., Leggett, W. C. (1984). Efficiency of large volume plankton pumps, and evaluation of a design suitable for deployment from small boats. Can. J. Fish. Aquat. Sci. 41: 1428-1435

Thorson, G. (1964). Light as an ecological factor in the dispersal and settlement of larvae of marine bottom inverte brates. Ophelia 1: 167-208

Tyler, M. A., Seliger, H. H. (1978). Annual subsurface transport of a red tide dinoflagellate to its bloom area. Water circulation patterns and organism distributions in the Chesapeake Bay. Limnol. Oceanogr. 23: 227-246

Tyler, M. A., Seliger, H. H. (1981). Selection for a red tide organism. Physiological responses to the physical environment. Limnol. Oceanogr 26: 310-324

Vogel, S. (1981). Life in moving fluids. W. Grant Press, Boston, Ma., USA

de Wolf, P. (1973). Ecological observations on the mechanisms of dispersal of barnacle larvae during planktonic life and settling. Neth. J. Sea Res. 6: 1-129

de Wolf, P. (1974). On the retention of marine larvae in estuaries. Thalassia jugosl. 10: 415-424

Wood, L., Hargis, W. J. (1971). Transport of bivalve larvae in a tidal estuary. In: Crisp, D. J. (ed.) Proceedings of the Fourth European Marine Biology Symposium, Bangor, 1969. Cambridge University Press, Cambridge, p. 29-44 